\title{
La tendencia del anti branding en la comunicación estacionaria de marcas. El caso de Día de Muertos en México
}

The anti-branding trend in stationary brand communication. The case of Day of the Dead in Mexico

A tendência anti-branding na comunicação de marca estacionária. $O$ caso do Dia dos Mortos no México

\author{
Florencia DAVIDZON \\ Centro y SNHU (México) \\ f.davidson@snhu.edu \\ https://orcid.org/oooo-0oo2-7431-5051
}

Chasqui. Revista Latinoamericana de Comunicación

N.o ${ }^{\circ}$ 48, diciembre 2021 - marzo 2022 (Sección Diálogo de saberes, pp. 239-258)

ISSN 1390-1079 / e-ISSN 1390-924X

Ecuador: CIESPAL

Recibido: 28-07-2O21 / Aprobado: 12-11-2021 


\title{
Resumen
}

¿Esta surgiendo un nuevo modelo para la comunicación de marca que le escapa a las máximas del modelo de posicionamiento definido y hegemónico que definiremos como el branding 2.0?

Hay indicios en diversas comunicaciones de marcas hoy, en variadas categorías, de una forma de comunicar que de manera premeditada para sus campaña "estacionaria" para día de muertos, opta por contradecir las máximas del modelo del canon, branding 2.0, y se aleja de su arquitectura de marcas, esto es, de enunciar a partir de los valores, la personalidad, el propósito de su marca, o de dar beneficios basados en atributos, o de ofrecer servicios buscando ser relevantes en la vida de las personas. Pareciera que lo que prima es proponer conversación y contenido de cualquier tipo inclusive de forma incongruente a sus marcas.

¿Construirá esto un nuevo modelo, una vía que valida la posibilidad del vaciamiento de significados de lo que tendría para decir -dejar de construir en el imaginario a partir de la enunciación de marca-? ¿Será esto una evolución del branding 2.0, un retroceso, o una tangente alternativa?

Palabras Claves: "Branding", "Día de Muertos", "Marketing Estacionario", “Modelos de Construcción de Marcas", "Posicionamiento", “Tendencia”.

\begin{abstract}
Is a new model for brand communication emerging that escapes the maxims of the defined and hegemonic positioning model that we will define as branding 2.0 ?

There are indications in various brand communications today, in various categories, of a way of communicating that in a premeditated way for its "stationary" campaign for the Day of the Dead, it chooses to contradict the maxims of the canon model, branding 2.0, and moves away from its brand architecture, that is, to enunciate from the values, the personality, the purpose of its brand, or to give benefits based on attributes, or to offer services seeking to be relevant in people's lives. It seems that the main thing is to propose conversation and content of any kind, even incongruously to their brands.

Will this build a new model, a way that validates the possibility of emptying the meanings of what it would have to say -to stop building in the imaginary from the brand enunciation-? Is this an evolution of branding 2.0, a setback, or an alternative tangent?
\end{abstract}

Keywords: "Branding", "Day of the Dead", "Stationary Marketing", "Brand Building Models", “Positioning”, “Trend”.

\section{Resumo}

Está surgindo um novo modelo de comunicação de marca que foge às máximas do modelo de posicionamento definido e hegemônico que definiremos como branding 2.0 ? 
Existem hoje indícios em várias comunicações de marcas, em várias categorias, de uma forma de comunicar que de forma premeditada para a sua campanha "estacionária" para o Dia dos Mortos, opte por contrariar as máximas do modelo canónico, branding 2.0, e se afasta de sua arquitetura de marca, ou seja, para enunciar a partir dos valores, da personalidade, do propósito de sua marca, ou para dar benefícios baseados em atributos, ou para oferecer serviços que busquem ser relevantes na vida das pessoas. Parece que o principal é propor conversas e conteúdos de qualquer tipo, mesmo incongruentemente com suas marcas.

Será que isso vai construir um novo modelo, um caminho que valide a possibilidade de esvaziar os sentidos do que teria a dizer -para deixar de construir no imaginário a partir da enunciação da marca-? É uma evolução da marca 2.0, um retrocesso ou uma tangente alternativa?

Palavras-chave: "Branding", "Dia dos Mortos", "Marketing estacionário", "Modelos de construção de marca", "Posicionamento", "Tendências".

\section{Introducción}

El propósito del siguiente trabajo es hacer un breve recorrido por la evolución de las conceptualizaciones de creación de marcas, lo que se presenta de manera teórica y se erige como el canon en el estado actual para ver cómo en la práctica en comunicaciones especificas estacionarias las marcas se permiten no acatar los mandatos teóricos; y pensar si con esta acción están o no construyendo un nuevo modelo.

Reflexionar sobre esto es importe porque con la revolución digital y el contexto de nuevos medios, el modelo de branding se ha intentado actualizar y consolidar en un modelo 2.0 que propongo llamar branding 2.0. Sin embargo aparecen ejemplos de casos que indican que no seguir el consejo del modelo también parece ser efectivo. Con ello, los resultados más inmediatos hacen que las empresas deciden obviar, o contradecir el modelo prescripto en busca de mejorar sus oportunidades de negocio.

El objetivo de este estudio es divisar las oportunidades de recrear el modelo actual de branding, y pensar si los indicios de casos que contradicen al modelo de branding2.0 ofrecen un entendimiento valioso para empezar a diseñar un nuevo modelo que evolucione e integre otras formas de pensar a las marcas. Determinar si esto emergente funciona como un modelo alterno, o puede convivir con el modelo branding 2.0.

La hipótesis de partida es que hay espacio para rever el modelo y empezar a teorizar con modelos de creación de marca superadores al branding 2.o. Además, que el instinto oportunista de los marketineros para explotar eventos estacionarios con activaciones no afianza ni contribuye a la salud de las 
marcas y en este sentido serian dos modelos diferentes a implementarse como dicotómicos, el tradicional o el alterno, pero no ambos.

\section{Un poco de historia, ¿De qué hablamos cuando hablamos de marcas?}

Si bien desde 1950 compañías como Procter and Gamble, General Food, Unilever y otras, venían ofreciendo sus productos y desarrollando sus marcas; desde los 90 se empezaron a establecer modelos y teorías para crear marcas a fin de construir valor soportados por el concepto de la diferenciación y para ellos buscando que en las comunicaciones sean memorables y consistentes en los usuarios consumidores.

Las marcas empezaron así a tener estrategia y con ellos personalidades. Algunas propuestas se enfocaron a crearlas a imagen y semejanza de las personas y a su anatomía; empezó a hablarse de marcas "humanas", "marcas de valores", "el ADN de marca", etc. También se han usado para la creación analogías a la construcción y a la arquitectura. Así se cuidaron los pilares básicos materiales y sus aspectos simbólicos inmateriales, y todo eso quedaba plasmado en la estrategia de la marca desde donde se procuraba desarrollar una comunicación con cierta vigencia en el tiempo -más allá de las innovaciones de los productos y servicios, o las necesidades coyunturales/tácticas-. A las marcas había que protegerlas, nutrirlas y obligarlas a que se manifestaran de forma consistente para elevar la identificación, el deseo, y la lealtad.

Esto se pensó y configuró en un contexto de medios masivos, donde la televisión era la reina, y donde la teoría de la comunicación que acompañaba la práctica era una comunicación lineal de emisor a receptor.

La argumentación principal, y modelos de creación de marcas, se inició intuitivamente por publicistas, y con el tiempo fue validada por los resultados de estudios de mercado y algunos estudios académicos que dieron cuenta de la elasticidad de la comunicación de marcas con las ventas ${ }^{1}$. Así, cuando más querible, más única, y diferencial era una marca más posibilidades tenía de ser adquirida y más dispuesta la gente estaba a pagar más dinero por un producto. Además, no solo avalaba una marca un único producto, sino que cultivar una marca y mantenerla robusta permitía tener un ancla de valor sólida en la mente y corazón de las personas para generar tracción y dar credibilidad en el lanzamiento de nuevos productos y servicios. Esto era válido tanto para una línea de productos afines como inclusive incursionar en nuevas categorías optimizando así inversiones. Las marcas contribuían desde esta mirada a impulsar con su presencia que dejaba en la mente y en el corazón de los receptores su esencia e identidad, a la creación de innovaciones y a sostener un diverso portafolio de bienes, tangibles e intangibles.

1 Keller Lane, Kevin. Consumer Research Insights on Brands and Branding: A JCR Curation 
Con la revolución digital, el marketing necesitó reformularse. En los últimos diez a quince años aproximadamente, se buscó primero convivir con la disrupción tecnológica intentando adueñarse de ella y amoldarla a su cosmovisión operativa. Pero poco a poco su evolución, su dinámica y con ello nuevas lógicas y principios, fueron creando nuevas prácticas y reformulando el contexto mediático y de comunicación.

Los publicistas entonces empezaron a hablar y usar un término -emulando el lenguaje de desarrolladores de plataformas-, el de "ecología de marca". Sin olvidarnos que para ese entonces desde la academia la teoría de la comunicación se volvía a despolvar la escuela de la ecología de medios y esta había empezado a cobrar nuevamente auge. Los publicistas se percataron de la necesidad de encausar a la autonomía del usuario-consumidor en una relación ya no lineal sino multidireccional para que siguiera habiendo e incrementándose la persuasión y las ventas. Por ello se empezó a desarrollar dentro de la cosmovisión de ecología de marca, el concepto de un relato único. Una narrativa rectora de marca que se debía expresar en los múltiples contactos que se tiene con los consumidoresusuarios. Esta perspectiva central fue adoptando diferentes términos, según sus autores por lo general desde un pensamiento desde los países centrales de habla inglesa: Narrative Brand Strategy, 36o, BrandActing, Brand Propose, el Branded Driven, BrandDoing, Storytelling, etc, y se fue estableciendo poco a poco como la nueva norma para generar sentido y dar valor.

Se fue consensuado y consolidando que una marca se construía y mantenía en vigencia cuando lograba aportar "sentido" en la vida de las personas y tener un rol. Si bien esto no era algo totalmente nuevo, asignarle este poder de construir un universo significante a una marca, esta idea de construir valor había estado acotada -y confinada- dentro del contexto mediático de los medios tradicionales.

Con los nuevos medios y su facilidad para generar relaciones interactivas, se resignificó la idea original agregándole ahora una visión más optimista, expansiva, adjudicándole a las marcas la función de dar también experiencias, acciones y servicios.

Así las marcas nacieron después de la segunda guerra mundial para diferenciarse de la competencia y delimitar una propiedad (de allí el término marca por la acción de marcar como se marcaba al ganado); se volvieron poco a poco en lo go iconos y metáforas de universos simbólicos, para en los últimos quince años ampliar esos universos acotados e irradiar valor hacia universos simbólicos expandidos.

Se estableció en la industria, y en las teorías de comunicación y marketing que acompañaron, que las marcas tenían conductas, poder de accionar. Ya no solo de forma directa y vivencial con los consumidores a través de las acciones en punto de venta, eventos, o encuentro planificados, sino que podían dar una experiencia continua en el contexto de la interacción digital.

Con la evolución de internet a comienzos del 2000, y en especial con las redes sociales lo que se define hoy como la web 2.o, la web orientada a la gente 
y lo social, y acompañándose en paralelo con el desarrollo y el crecimiento de la industria de videojuegos; el marco teórico del branding "storytelling" o "narrative branding" es lo que podríamos llamar hoy el canon del branding.

La revolución digital, junto al aggiornamiento de marca y la reconfiguración que encontraron los publicistas, las incipientes agencias digitales, los estudios de diseño y algunas consultoras, quienes pronto se volvieron en salvaguardas de las marcas resolvieron adaptarse de esta manera a la cuarta revolución, la digital, y parecería que la argumentación era sólida y daba resultados, si se actuaba según la prescripción. Siguiendo un proceso de manera planificada, cuidada, partiendo de la ingeniería, y el diseño de la misma, creando "la semilla" - analogía del mundo ecológico- donde esta la esencia de la marca, y luego "nutriendo" su crecimiento, estimulando su habla direccionada, y haciéndola actuar de forma "orgánica", así el branding daría "frutos" y resultados en ventas.

Además toda marca debería regirse por varios principios, escritos y no escritos, entre ellos ofrecer utilidad, honestidad, presencia, accionar o actuar al servicio de sus usuarios-consumidores, tanto como ser lúdicas. Esto último sería saber jugar en el juego de la sorpresa, la persuasión, el de contar historias, y dar mensajes positivos que llamen la atención.

Para ello hablará desde su personalidad, valores, creencias y una visión particular para entablar relaciones y conversaciones con sus públicos. Hay dos abordajes, en el mejor de los casos las marcas lideres son las que pueden proponer y como héroes, hacer caminos. Pero también esta la vía para las marcas de repetir lo que ya existe en la sociedad, y al tener presente una necesidad, una preocupación, o una tensión de la audiencia ofrecer un universo significante de manera creativa que resuelva esa situación. En ambos casos, se buscará que la identidad aporte a la solución, y la amplificación de esta existencia sea consistente en toda la ecología de medios en la que se presenta.

Hasta aquí lo que parecería ser el patrón, la norma establecida. Una marca debía tener un nombre, un posicionamiento, una identidad definida en una arquitectura, cobrar una existencia imaginada a partir de un engranaje asociado al producto o servicio que representaba esa marca, de una categoría especifica, o diversa de productos. Inclusive como se mencionó, a partir del 2000 la evolución a ofrecer estilos de vida, ideologías, una actitud y una mirada particular del mundo. Siguiendo estos mandatorios se desarrollaba una marca orgánica y centralizada con una identidad consistente que acrecentaba valor. Inclusive cuando se hacia aparecer, o hacer hablar, a las marcas en eventos tácticos de promociones, ediciones especiales, etc. Quizás el caso más emblemático de esto es Coca Cola con sus campañas de branding consistentes y sus eventos de marketing estacionario como los eventos deportivos de futbol, o navidad, donde se vuelve a abordar y reforzar los mismos valores, con la misma personalidad, y estilo que nos ha acostumbrado a partir de su esencia marca todo el año.

Ahora bien, ¿Qué esta pasando con este canon de pensamiento y práctica del branding 2.0? 


\section{¿Puede el Antibranding arrojar resultados positivos?}

Analizamos diversos casos de comunicación y acciones de marcas en México de lo que se denomina "marketing estacional" siguiendo las campañas especiales, o tácticas, de Día de Muertos durante el 2019 y 2020.

Encontramos ejemplos de lo que podría se una tendencia que nos resulta significativa de observar y estudiar.

Este fenómeno apareciera abrirnos la posibilidad de pensar en la existencia de otra manera de hacer comunicación inscrito en un modelo nuevo, o un modelo o alterno no escrito que pudiera estar desafiando al canon de lo que prescribe y define en el branding 2.0.

Nos preguntamos ¿Esta surgiendo un nuevo modelo de hacer branding, un modelo que de forma premeditada elige contradecir a las máximas prescriptivas para construir marcas: actuar regidos pro el propósito, los valores, la honestidad, el servicio, etc.? ¿Es esta modalidad que se nos presenta como ejemplos de antibranding por su vaciamiento de significado sobre contenidos congruentes con el enunciatario (sus Brand Equities, etc) una evolución del branding 2.0 en el contexto del marketing digital? ¿Es que en lógica de generación de contenido, cualquiera sea este, tiene más peso y antecede a la identidad de la marca?

\section{Metodología}

A través de la semiótica y del análisis del discurso de la comunicación de marcas durante el mes previo al Día de Muertos en el 2019, y sobre todo el 2020, estudiamos el tipo de comunicación y actividades especificas que tienen las marcas asociadas a lanzamientos especiales que apelan a la festividad.

Además, analizamos de qué manera las marcas construyen y representan la identidad y la cultural mexicana en sus avisos, en sus elementos más significantes (icónico y textuales).

Para ello abordamos los discursos teniendo presente diversas dimensiones de análisis. Así, deconstruimos los materiales en cuatro categorías (sin privilegiar niveles).

El primer nivel, su contexto de comunicación (¿En qué medios aparecieron?). El segundo, el tipo de enunciador construido (¿Cómo aparece la marca allí?). El tercer, el tipo de destinatario o target definido en el discurso (¿A quiénes le hablan?) y el cuarto, la industria o categoría del enunciador.

En relación al nivel uno, observamos o a las comunicaciones en los contextos de comunicación en diversos medios, pero sobre todo digitales ya que allí donde todas las marcas tienen mayor o exclusiva presencia. Pareciera que en la comunicación estacionaria no se invierte casi en realizar contenido de alta inversión en producción audiovisual, ni se hacen grandes apuestas de pautas en medios.

Sobre el enunciador, el dos, deconstruimos la marca para ver qué mensajes construyen, qué dicen de si mismas, cómo presentan atributos, y beneficios. 
Cómo miran la vida, sus valores, sus creencias, y su personalidad. ¿Qué propone como mensaje? Y qué tipo de rol parecen ofrecer tener en la vida de las personas. (Todos los elementos que conforman las bases del branding 2.0)

En el tercer nivel, abordamos el aspecto del destinatario, buscamos una muestra diversa en las edades: niños, jóvenes, adultos y adultos mayores. Pero nos resultó difícil encontrar comunicación para adultos y adultos mayores. Esto de por sí resultó interesante y un gran hallazgo.

Para abordar el nivel cuatro, nos focalizamos en el análisis sobre las categorías de bebidas alcohólicas (marcas como Tequila José Cuervo, Cervezas: Victoria, e Indio), ropa deportiva (marcas como Nike, Vans, y Adidas), juegos y juguetes (marcas como Barbie, Play-Dah), alimentos y bebidas (marcas como Starbucks, Kellogg's, La Costeña, Ricolino, Fanta, Coca, Pepsi, Nutella, etc.), cerillos (Flama) entre otras.

Los hallazgos y las conclusiones a las que llegamos sobre los alcances de la comercialización en México del día de muertos y la estrategia de las marcas permiten resultados que esbozan que hay marcas que se expresan de manera oportuna para expandir su discurso de marca de forma consistente, mientras hay otras que comunican de manera oportunista desapegados del modelo del branding 2.0, esto último pudiera estar siendo efectivo ya que son comunicaciones y acciones que se repiten año con año; se incrementan y expanden. Por consiguiente podríamos empezar a hablar de una tendencia hacia otra forma de hacer branding.

\section{Resultados}

Hace algunos años se viene resignificando el día de muertos, en particular a partir del cine con la película James Bond, 007 Spectre (2015). Este enunciador le adicionados elementos al relato colectivo, y le ha impreso ciertas hibridaciones. Esta narrativa cinematográfica le adjudicó ritos a la festividad no propios a las costumbres mexicanas sino más afines a las prácticas de Halloween. Otra película, esta animada y creada por Disney/Pixar, Coco (2017), también ha contribuido con una nueva mirada sobre la festividad, y al ficcionalizarla agregarle una versión propia donde se sugiere una festividad de características homogeneizantes.

Todo esto, tal vez, ha contribuido a que las marcas en México decidan también explotar estas fechas para volverla una fuente más de comercialización de sus productos, servicios y de sus narrativas en estas fechas. Poco parece importarles hoy a algunas de ellas, qué significaba, o significa aún hoy esta festividad para la gente que tradicionalmente la conmemora. $\mathrm{O}$ bajo qué insights descansan hoy las razones por las que el $62 \%^{2}$ de los mexicanos celebran de forma tradicional. Y menos aún preguntarse cómo sus marcas pueden o no articular de forma

2 Estudio de Consultora, GCE, 2020, https://www.animalpolitico.com/2012/10/8-de-cada-10-mexicanosprefieren-dia-de-muertos-sobre-halloween/ 
orgánica su universo significante de marca con universo del imaginario del día de muertos.

El Día de Muertos en México en el pasado nunca había sido un momento ni para hacer una celebración expansiva, ni para hablar de disfrute, ni para beber, ni para festejar con disfraces, ni para regalarse dulces, ni para consumir indumentaria, juegos, etc. Siempre había sido una celebración asociada a rememorar a los familiares que ya no están. En este sentido los motivadores de la población allegada a la festividad, eventual usuaria de productos y servicios para estas fechas era conmemorar a sus muertos, y reencontrarse con ellos simbólicamente, en esos "días santos" en altares donde se realizan ofrendas típicas de alimentos y flores. Es de esperarse que con los años las cosas se transformen y una fiesta se modifique, pero inusual que las marcas propongan practicas que generan una metamorfosis de lo cultural a fin de encontrar su presencia en ella.

A los principios del siglo 20 con el intento de consolidación del Estado Nación Mexicano, tras los años de lucha y de revolución, el Día de Muertos se intentó recuperar y resignificar para convertirlo en una festividad que dio identidad a los mexicanos y solidificó la unión bajo ese imaginario común en el proyecto de transformación cultural de Vasconcelos en los años 20. Claro esta que nunca existió una sola manera de celebrar día de muertos y según las regiones y las herencias culturales se realizaban y aún se realizan diferentes rituales. Pero poco a poco en el imaginario de lo mexicanos se creo la idea de una tradición indígena, con mestizaje católico español y con aportes de la idolología Estatal la festividad ayudaba a reforzar la identidad nacional. Esta es la que ha logrado preservarse a lo largo de los años a través de la creación de un universo simbólico que hoy en el mundo global y el contexto de los nuevos medios se esta transformando.

El proceso de representación y mediatización a través de símbolos se dio al comienzo de la consolidación del Estado Nación haciendo uso de la imagen de la catrina. Una imagen que había sido ilustrada por primera vez en 1912 por el caricaturista, José Guadalupe Posadas y que éstele había asignado connotaciones muy diferentes, a las que le dio en su recreación, uso y divulgación masiva luego Diego Rivera en los murales.

Para el primer creador de la imagen, la catrina se llamó la calavera garbancera. Para él, representaba a la muerte, la que les llega a todos y siempre esta presente. Tenía alta critica social: "La muerte es democrática, ya que, a fin de cuentas, güera, morena, rica o pobre, toda la gente acaba siendo calavera" dijo su autor. El artista quiso crear en su estilo de hacer caricatura y critica, sátira social. Algo que empezó a borrar un poco en su uso y re creación Diego Rivera al llamarla "la Catrina" (en el mural: "Sueño de una tarde dominical en la Alameda Central”). La diferencia radica en el uso de la imagen en tiempos diferentes. José Guadalupe Posadas, lo que propuso en "La calavera Garbancera" era una burla de la situación económica, política y social durante los años del Porfiriato (1876- 
1911). Por ello los esqueletos eran una forma irónica para criticar la situación del país de esos años para denunciar los hábitos de las clases privilegiadas a quienes se les recordaba que no importaba el status económico que se tuviera, que al final todos éramos iguales en la vida y en la muerte. Al mismo tiempo le servía al creador para señalar a los indígenas que se habían acomodado en el sistema imperante en el poder y pretendían alejarse de su raíces y tradiciones, por eso usó vendedores de garbanzos como metáfora de los indígenas pobres que aparentaban ser otra cosa alejándose de sus raíces indígenas. Mientras que la versión de Diego Rivera, fue mucho más adornada, con flores llamativas, vestidos elegantes, e inspiración para proponer desde el Estado la tradición de disfrazarse de catrinas. Y aunque continuaba la critica social ya que Catrina como nombre viene del traje de la aristocracia que es lo que esta en cuerpo de la calavera y se llamaban Catrín fue de la autoría del muralista.

Esto viene a cuento aquí, ya que la catrina con los años se volvió el gran icono de la festividad hoy y se expande en los medios digitales, con nuevas representaciones, estéticas y con nuevos significados.

Hoy en las comunicaciones de día de muertos todas las marcas de manera consistente hacen uso de catrinas, altares, y flores naranjas como emblemas de la festividad. Cada marca hace una apropiación creativa y particular según su visión y necesidad. Claro está, en ninguno de todos los usos de las marcas comerciales se recupera el sentido de critica social o reclamos sobre la equidad de los vivos en esta vida. Solo sobre esto último parecen hoy apelar las campañas de anunciantes de algunos colectivos feministas que empezaron a usar el día de muertos para hacer comunicación y generar agenda sobre su lucha activista en contra de los feminicidios hablando de "Día de Muertas", recuperando también el icono de las catrinas, las flores y los colores de los papeles picados de los altares ${ }^{3}$.

En relación al otro símbolo el de los altares. En la práctica cada altar es diferente y depende de a quién esta dedicado sus características, pero en general contienen algunos elementos específicos. Normalmente se pueden encontrar en altares: veladoras, incienso, sal, pan de muerto, fotos, comida, papel picado, flores de cempasúchil y calavera de azúcar. Estas cuestiones después de más de 100 años de comunicarse y visibilizarse desde el Estado, resultan lo elementos emblemáticos tradicionales.

Los significados estarían asociados a: Las veladoras la representación de la luz, para guiar a las almas de los difuntos y que éstos encuentren su camino. El incienso, se usa para limpiar y purificar el lugar y ahuyentar a los malos espíritus. La sal con un rol también de purificación. El pan de muerto, de características redondas para representar el ciclo de la vida y la muerte. Además su diseño con bolitas y tiras representaría los huesos del cuerpo humano. Las calaveras de azúcar hacen referencia a la muerte siempre presente. También

3 https://verne.elpais.com/verne/2018/10/24/mexico/1540407307_544064.html 
esta el papel picado colorido o papel de seda recortado que invita al aire a la ofrenda. Finalmente, las flores naranjas de cempasúchil de adorno del altar y cuando se colocan en forma de camino son una guía para el difunto.

Las marcas simplifican por lo general todos estos elementos y lo reducen representar con las veladoras, el papel picado colorido, las calaveras de azúcar, destacándose siempre muchos las flores de cempasúchil.

\section{¿De qué hablan y tematizan las marcas?}

Encontramos algunas temáticas recurrentes en los mensajes de marcas en dos ejes. Lo que podría ser más lúgubre del encuentro con el pasado, y lo más alegre y festivo para la conexión entre los presentes.

El primer eje están Victoria, Flama, La Costeña, Cuervo Tradicional, Starbucks, Kellogg's, Cemex, Coca Cola, Pepsi, indio, etc. Es el más recurrentes es apelar a la unión y la familia. Las marcas buscan construir sobre el valor de la tradición y la mexicanidad. Invitan con sus mensajes a "vivir las tradiciones", invitan a "despídete de tus familiares”, o "acércales una vela". Se suele apelar al "orgullo mexicano" donde los enunciadores dicen estar motivados por querer "honrar" a las familias mexicanas. Indio ${ }^{4}$, además de su campaña de colección de barrios por internet, crea una acción especial sobre el concepto de "tradición que se mantiene viva" donde ofrece una serie con videos de entretenimiento llamada "Guardianes de los muertos" donde de manera animada le dan vida al símbolo del logo de la marca un emperador indígena (que alude a Cuauhtémoc), donde la propuesta narrativa es darle al último emperador mexica el rol de guardián de los difuntos en su camino de retorno.

En el segundo eje encontramos ejemplos de marcas (Fanta, Play Doh, Tic Tac, Ricolino, Barcel) con mensajes más asociados a tradiciones de festejos que apelan a lo lúdico y la diversión en especial asociados e influenciados por rituales de otras culturas como Halloween, "píntate", "disfrázate" "baila", "diviértete".

Y aquí una sub-dimensión robusta de marcas (Nike, Cuervo, Indio, Nutella, Barbie, Adidas, Vans, Comex, Doritos, etc) que apelan al "consume", asociado al concepto de "colecciona", que van unidas a lanzamientos y propuestas de "memorabilia" que suelen ser más celebratorias del presente, de los vivos, sus talentos, su ingenio, su color.

\section{¿Tiene esta comunicación asociada a la festividad una presencia en diversidad de medios?}

Por lo general se focaliza en medios digitales, privilegiándose Facebook, Instagram, YouTube y en menos medida Twitter. La comunicación estacionaria no suele ser una comunicación que se pauta en los medios tradicionales, salvo

4 https://indio.com.mx/etiquetasdiademuertos2020/\#/ 
cuando esta inscripta en una comunicación que sigue el pensamiento de una estrategia de marca en branding 2.0 como es el caso de Victoria. Sin embargo el uso digital y los lanzamientos especiales que las marcas hacen sobre estas festividades resultan muy significativas.

\section{¿Es una festividad que la industria contempla un destinatario multi-target?}

La comunicación va dirigida principalmente a un público joven o infantil, interpelan y construyen una audiencia o destinatario sin hacer distinciones de géneros o clases sociales. Además no aparecen diferencias en la identidad cultural u orígenes de los mexicanos receptores aunque suelen apelar a un público moderno y urbano y para ellos se utilicen contenidos que reflejan rituales y o prácticas de una zona en particular.

Podemos observar cierta asociación más afín a mensajes "festivos" y celebratorios del presente, en la comunicación dirigida a jóvenes, frente a mensajes más "lúdicos y que apelan a la diversión” en públicos infantiles.

\section{¿Qué construyen las marcas de sí mismas?}

En la deconstrucción de las comunicaciones y acciones de marca, sobre todo sus discursos directos o a través de influencers en redes logramos profundizar sobre el análisis sobre posibles pilares del modelo del branding 2.0 (Insights, Atributos, Beneficios, Valores, Acciones, Promesa), para dar cuenta de distancias y cercanías a él.

\begin{tabular}{|c|c|c|c|c|c|c|c|}
\hline & José Cuervo & Victoria & Indio & La Costeña & Kellogg's & Nike & Barbie \\
\hline $\begin{array}{l}\text { Insights* } \\
\text { (inferidos para } \\
\text { comunicación } \\
\text { estacionaria) }\end{array}$ & \begin{tabular}{|l} 
"Quiero \\
homenajear \\
a mis seres \\
queridos"
\end{tabular} & $\begin{array}{l}\text { "Es un } \\
\text { orgullo ser } \\
\text { mexicano" }\end{array}$ & $\begin{array}{l}\text { "Ser mexicano } \\
\text { es estar } \\
\text { próximo al } \\
\text { origen de la } \\
\text { cultura pre } \\
\text { Hispánica" }\end{array}$ & $\begin{array}{l}\text { "El sabor } \\
\text { tradicional } \\
\text { nos } \\
\text { constituye } \\
\text { como } \\
\text { mexicanos" }\end{array}$ & $\begin{array}{l}\text { "Quiero } \\
\text { desayunar } \\
\text { de manera } \\
\text { diferente } \\
\text { con el sabor } \\
\text { tradicional" }\end{array}$ & $\begin{array}{l}\text { "Todas las } \\
\text { culturas } \\
\text { tienen lo } \\
\text { suyo para } \\
\text { mostrar" }\end{array}$ & $\begin{array}{l}\text { "Quiero } \\
\text { muñecas, } \\
\text { de mi } \\
\text { cultura" }\end{array}$ \\
\hline Atributos & $\begin{array}{l}\text { Diseño de } \\
\text { botellas. } \\
\text { Origen } \\
\text { mexicano } \\
\text { del Agave. }\end{array}$ & $\begin{array}{l}\text { Rediseño } \\
\text { de } \\
\text { empaques. } \\
\text { Sabor } \\
\text { tradicional }\end{array}$ & $\begin{array}{l}\text { Logo } \\
\text { Emperador } \\
\text { Nombre de } \\
\text { Marca }\end{array}$ & $\begin{array}{l}\text { Portafolio } \\
\text { de salsas } \\
\text { típicas. }\end{array}$ & $\begin{array}{l}\text { Cereal con } \\
\text { sabor de pan } \\
\text { de muerto* } \\
\text { (que no } \\
\text { resulto el } \\
\text { esperado) }\end{array}$ & $\begin{array}{l}\text { Diseño } \\
\text { tenis día de } \\
\text { muertos en } \\
4 \text { versiones } \\
\text { con colores } \\
\text { inspirados en } \\
\text { altares. }\end{array}$ & $\begin{array}{l}\text { Muñecas } \\
\text { pintadas en } \\
\text { las caras, } \\
\text { edición } \\
\text { especial } \\
\text { Catrina }\end{array}$ \\
\hline Beneficios & Conmemorar & $\begin{array}{l}\text { Conme- } \\
\text { morar }\end{array}$ & $\begin{array}{l}\text { Conexión al } \\
\text { Origen }\end{array}$ & $\begin{array}{l}\text { Ofrendar } \\
\text { Comida }\end{array}$ & $\begin{array}{l}\text { Sabor a } \\
\text { tradición en el } \\
\text { desayuno }\end{array}$ & Identidad & $\begin{array}{l}\text { Coleccio- } \\
\text { nable }\end{array}$ \\
\hline Valores & Tradición & $\begin{array}{l}\text { Orgullo } \\
\text { Identidad } \\
\text { Mexicana }\end{array}$ & $\begin{array}{l}\text { Orgullo Pre } \\
\text { hispánico }\end{array}$ & $\begin{array}{l}\text { Tradición } \\
\text { Mexicanidad }\end{array}$ & Tradición & \begin{tabular}{|l} 
Creatividad/ \\
Autenticidad/ \\
Potencial
\end{tabular} & $\begin{array}{l}\text { Potencial/ } \\
\text { Identidad }\end{array}$ \\
\hline Acciones & $\begin{array}{l}\text { Conjuntas } \\
\text { con Spotify }\end{array}$ & - & $\begin{array}{l}\text { Entreteni- } \\
\text { miento }\end{array}$ & - & - & $\begin{array}{l}\text { Exportar al } \\
\text { mundo }\end{array}$ & - \\
\hline
\end{tabular}




\begin{tabular}{|l|l|l|l|l|l|l|l|}
\hline Promesa & $\begin{array}{l}\text { Un país que } \\
\text { va al futuro } \\
\text { sin olvidar su } \\
\text { pasado. }\end{array}$ & $\begin{array}{l}\text { Lo que } \\
\text { nos hace } \\
\text { mexicanos }\end{array}$ & $\begin{array}{l}\text { Protector de } \\
\text { la tradición y } \\
\text { del camino del } \\
\text { difunto a su } \\
\text { altar }\end{array}$ & $\begin{array}{l}\text { El sabor de } \\
\text { México para } \\
\text { la eternidad }\end{array}$ & $\begin{array}{l}\text { Innovación de } \\
\text { tu desayuno } \\
\text { con todo } \\
\text { el sabor } \\
\text { tradicional }\end{array}$ & $\begin{array}{l}\text { De México } \\
\text { para el } \\
\text { mundo / Para } \\
\text { mi familia }\end{array}$ & $\begin{array}{l}\text { Inspirando } \\
\text { a Niñas } \\
\text { desde 1960 }\end{array}$ \\
\hline
\end{tabular}

Resulta muy evidente que ni Nike ni Barbie son marcas que tienen algo que ver en sus escencia con las particularidades de la festividad y la aplicación del modelo branding 2.o esta bastante forzado; los alimentos hacen su mejor intento pero también resultan forzados, mientras las marcas asociadas a las bebidas alcohólicas logran encontrar cierta sinergia desde su modelo de branding $2.0 \mathrm{y}$ su presencia en la conmmemoración anual.

\section{¿Qué relación hay entre las categorías de productos-marcas con el Día de Muertos?}

Para contestar esta pregunta que resulta central es importante dar cuenta de los elementos claves de la festividad y el arraigo y significados de la misma en la población.

Como se mencionó al comienzo no es una fiesta de celebración sino es una conmemoración anual a los difuntos, que si bien no es lúgubre y puede ser distendida, de convivio familiar, etc. su razón principal desde sus inicios, y en particular con la recreación impulsada por el Estado Mexicano para generar unidad nacional bajo la idea de una única identidad nacional en el S.XIX, ha sido recordar a los muertos y estar cerca de ellos, homenajearlos, porque son días de reunión donde se reza, se conversa y se acostumbran cantar canciones típicas, o las que les gustaban a los difuntos. Y se ha usado para ellos tres ejes simbólicos las catrinas, los altares y las flores.

Las marcas y según sus categorías revisitan este significante construido, lo usan, reconfiguran y tergiversan a sus necesidades de esta manera se acercan y afianzan en el modelo del canon del branding o deliberadamente se apartan de él. Abordaremos a las bebidas alcohólicas, los alimentos, la indumentaria y juguetes.

Las bebidas alcohólicas, por ejemplo, históricamente han creando marcas con poco apego a los intrínsecos de sus productos para construir en su comunicación universos significantes siguiendo el modelo del branding 2.0 evocativo o aspiracional de un mundo (incorporando todos los elementos del modelo: narrative branding asociado a un universo simbólico con valores, personalidad, promesa, esencia de marca etc.) Y en el caso del Día de muertos suelen no trabajan sobre los insights para el resto del año, apelando a las tensiones de sus consumidores donde las bebidas resuelven con su consumo a modo de beneficios. Entonces si bien es una de las categorías más próximas al modelo de branding 2.0, para día de muertos no se apela ni se abordan cuestiones como la autoestima, la identidad o pertenencia a un grupo de pares, 
sino más bien la convivencia y la identidad más expansiva, de la tradición, del carácter cultural de forma más general.

El Tequila, José Cuervo5 ${ }^{5}$ una marca que viene lanzando una edición especial diferente cada año para estas fechas, en su comunicación del 2020 justifica su campaña de esta manera: "Creamos la edición José Cuervo Tradicional Calavera una edición que representa una de las tradiciones de la cual nos sentimos más orgullosos a nivel mundial. Una celebración llena de color, sabores y esencia mexicana. De un país que ve hacía el futuro sin olvidar su pasado".

Observamos dos cuestiones importantes. La primera es que la marca que todo el año suele construir su posicionamiento a partir del valor y conceptos asociados a "tradición" usa a la festividad de manera consistente para incrementar este valor durante la celebración. Sin embargo el rol del Tequila en la celebración no ejerce relación alguna, siendo que no es una celebración para brindar, ni festejar bebiendo. Por otro lado, cuando se habla de "llena de sabor, color y esencia mexicana" y además se usan en la ediciones especiales en las botellas, iconos de catrinas modernos, estan recreando y resignificando la misma tradición que dicen conmemorar. Además como se dijo, no es una festividad realmente de sabores -más que el pan de muerto típico para las ofrendas que no se lo come la gente sino se ponen en un altar; al igual que el azúcar,- y los colores, si bien hay cierta diversidad, el naranja y el morado son los colores más presentes, los de las flores cimpachuli de las ofrendas y tal vez algo del papel picado morado.

La recreación se realizó entonces de manera libre, o con permisos, y esta resignificación que se inscribe de las catrinas en las botellas de José Cuervo también presenta una mirada propias de la mano del artista que se convocó para diseñarlas. Esta estrategia de comunicación de José Cuervo se lanzó a través de las redes sociales donde se dio a conocer el diseñado de Tavo Santiago en Instagram y Facebook principalmente. Además acompañaron sus esfuerzos en una acción en colaboración con Spotify, donde se ofreció un playlist creado por Casa Cuervo con las "mejores canciones del momento" usandose el \#Díademuertos con ritmos únicos. Lo que no podrían ser ritmos únicos siendo que las músicas típicas son por principio colectivas, compartidas y populares al ser típicas de las fiestas.

La propuesta de la marca no esta necesariamente anclada en los insights de la cultura, ni en las necesidades y motivaciones de la población que celebra esta tradición. Y aunque hayan recreado en su útima botella parte de la tradición de limpieza de huesos que se hace en un rito particular de la cultura maya de la comunidad de Yucatán en una celebración que se llama Hanal Pixan. Tampoco tiene relación alguna con la critica social original del icono de la calavera de Posadas ni la catrina de Diego Rivera para solo hablar de una marca que se

5 Campaña José Cuervo. https://www.youtube.com/watch?v=_4odAXAMnzA, https://www.youtube.com/ watch?v=|z5ogMp8oOY) 
preocupa por las "tradiciones". Estas cuestiones tal vez invitarian a reveer el modelo del canon del branding 2.0.

Otras marcas que sí logran quedar más adentro del canon como se dijo son las cervezas. Victoria ${ }^{6}$, con su campaña "Chingonas hasta en la muerte" y luego "Los que nos hace mexicanos" o Indio con "Barrio de los Muertos" o "Guardianes" parecen ser más orgánicos y más fieles a sus marcas y en este sentido a lo que se estableció como modelo del canon. Y le han encontrado un rol activo a sus productos-marca dentro de la festividad al proponer incluirla en el ritual y darla como ofrenda en el altar. En especial Victoria, y tal vez por esto, es la única de todas las marcas que se atreve a invertir año con año y hacer comunicación con una pieza tradicional audivisual para esta fecha, teniendo una estrategia de lo más alineada y propia al branding 2.0

Uno de los intentos más forzados se dio en la innovación de productos ideada por, Kellogg' $\mathbf{s}^{7}$ con el lanzamiento de su cereal con sabor a "pan de muerto", que no resultó funcionar como producto y que desde la comunicación se ofreció con una ideantidad lúdica, más afin a halloween que día de muertos.

Otro intento forzado podría ser $\mathbf{L a}$ Costeña ${ }^{8}$, una marca de enlatados y salsas, interesada en construir su valor de marca asociada a la identidad nacional y la "mexicaneidad". Ellos ligan a su marca con la festividad diciendo: "el sabor de mexico para la eternidad" y de esta manera ofertan su porfolios completo de productos dentro del altar.

Finalmente, uno de los casos menos forzados, serían los cerillos Flama ${ }^{9}$ que justifican su presencia, su comunicación y rediseño de empaque, al evidenciar que su producto es necesario para encender las veladoras en los altares, y pueden de esta manera comunicar: "enciende una flama para los que ya no estan".

Resulta emblemático que existan acciones y comunicaciones de marcas de otrascategorías, menosafinesalafestividad, quequieran sumarsealacelebración como las de indumentaria, juguetes. Categorias que suelen comunicar otro tipo de mensajes el resto del años y tener otro tipo de personalidad y valores que suelen privilegiar que resultan incosistentes y alejados a su posicionamiento e inclusive totalmente fuera del branding 2.0

Pensemos en Nike $\mathbf{~}^{\mathbf{1 0}}$, una marca muy alineada a generar valor siguiendo las máximas del canon, y precursora o lider del canon en muchos sentidos. En tiempos normales, es una marca que se acepta pero se percibe de origen extranjero sin relación alguna con las tradiciones mexicanas ni la festividad, ques hace brainding 2 .o comunicando sobre su ideologia, creencias, o propositos asociado a expandir el potencial humano, celebrando las acciones fisica, la innovación tanto de atletas como no atletas.

6 Campaña Victoria, https://www.youtube.com/watch?v=jziyHWsNGIE.

7 Campaña Kellogg's https://www.publimetro.com.mx/mx/noticias/2020/08/17/pan-muerto-en-cereallo-nos-faltaba.html

8 Campaña La Costeña, https://www.youtube.com/watch?v=c-OTYacliCA.

9 Campaña Flama, https://www.facebook.com/watch/?v=962836927572816.

10 Campaña Nike, https://www.youtube.com/watch?v=qtTHP7L3bwc. 
Esta misma marca decide incursionar en el día de muertos y hacer ediciones especiales de tenis inspirados en las ofrendas, sus colores y símbolos; en especial el papel picado y los colores de las flores naranjas del cempasuchils para el mercado local y para exportación. Y también optó por usar principalmente a los medios digitales dirigida al público joven, y a través de tres intermediarios o influencers lanzó su campaña digital en tres medios diferentes.

Construyen así para su divulgación una campaña bajo el concepto: "De México para el mundo" cuyo slogan fue "Para mifamilia" donde se evocó el amor que existe entre los miembros de una familia, entre los vivos y los difuntos, a fin de : "honrar la tradición mexicana".

Pero, ¿Qué de todo esto se relaciona con los valores de marca, con los instrisecos de la categoria, o dónde embona con los motivadores de los usuarios en esta festividad? ¿Cuál sería el rol del producto acá?

Algunos de los enunciatarios responsables de la acción, los influencers en las redes, dicen haber elegido honrar a la tradición mexicana y a los lazos familiares y esto pareciera estar bastante alejado del posicionamiento de marca ¿Qué tiene en común el celebrar el potencial, la innovación, la creatividad con conmemorar tradiciones de un lugar que no es propio? ¿De qué cuestiones de su ADN de marca se agarran para hablar de la familia, de la unión, cuando se han esforzado por años en hablar sobre la diversidad, la unicidad de cada persona, la autenticidad y el valor del esfuerzo?

Otro caso emblemático resulta, Barbie ${ }^{11}$, una marca que ha sacado una edición especial para las fechas. Se trata de una muñera vestida de catrina, como homenaje al personaje que desde su creación hasta nuestros días, y su presencia como algo lúdico y de moda que en las redes sociales se ha consolidado.

\section{Discusión. Del branding 2.o a un modelo alterno de comunicación de marcas.}

El hecho de casos que resultan exitosos como José Cuervo, pero sobre todo Nike, Adidas, o Barbie, que hablan del poder de mercantilizar una cultura a través de una oferta de productos alejada a los ingredientes que los componen desde el branding 2.0, nos invita a reflexionar si este modelo está acabado o podría evolucionar el pensamiento sobre el branding contemporáneo.

Lo que parece estar claro es que no hay una sola fórmula de hacer marketing y que el branding no es el principio rector o único para la toma de decisiones hoy.

Se requieren nuevos estudios, talvezjunto a consumidores y no consumidores para seguir estudiando este fenómeno desde la recepción.

El siguiente análisis nos arroja luz sobre la posibilidad de otros modelos por armarse, escribirse y teorizarse sobre la construcción de marcas donde la

11 Campaña Barbie, https://www.youtube.com/watch?v=3xJ6GLoKSKg 
máxima pueda ser la no consistencia, los mensajes no univocos, o de una sola voz, y que no por eso se perdería valor.

No podemos generalizar acerca de la invalidez hoy del branding 2.0, pero si abrir la puerta a la posibilidad de innovar en las teorías, y hacer reingeniería de los modelos o frameworks con los que se intenta seguir construyendo marcas.

\section{Conclusiones}

Una reflexión adicional que pudiera hacerse es si las marcas estan siendo oportunistas y lo que hacen con su accionar es apropiación cultural y o explotación de las tradiciones. Actuan como enunciadores en el capitalismo digital recreando iconos, mercantilizando y creando moda alejada de la escencia de la tradición y status quo para una cultura; ya no de masas sino interactiva, participativa de prosumidores.

A esta crítica responderá una contra-corriente de autores que responderá que estan en sus derechos de hacerlo, ya que nadie es dueño de una cultura, y no existe la idea de esencia única de una sola tradición, o que la cultura siempre esta viva en un proceso de resignifiación, en circulación a través de múltiples enunciatarios que se influencian por igual. Además, por otra parte y para rematar el debate dirán que los objetivos del marketing no tienen como prioridad mantener las tradiciones sino generar ventas y para esto les es válido adoptar y legitimar un formato que existe en la cultura y utilizarlo a su parecer, si en el pasado lo hizo el Estado, ahora lo podrían hacer las marcas.

Pero esta discusión no ha sido el foco de este ensayo. Sino más bien pensar si las marcas al elegir desarrollar acciones, hablar asociándose a una festividad estacional, y generar contenido sobre el día de muertos lo hacen o no siguiendo el manual de branding 2.o. Todo indica que se permiten salir del canon y esto no les acarrea efectos negativos, por el contrario. Por consiguiente se podría precindir del modelo, que probaria no ser eficaz o indispensable.

Tal vez así se demostraría que se pueden generar ventas y hacer campañas "tácticas" (una acción extraordinaria en el año que no es orgánica al branding del resto del año) alejándose del canon del branding 2.o. Porque si crear marcas en el pasado era generar diferenciación en los contextos de abundancia, hoy generar contenidos se ha vuelto más importante, y resulta prioritario enunciar diciendo cosas en el contexto de turbulencia, sin importar tanto quien es el que habla y qué tiene para decir desde su esencia.

La gran pregunta sin embargo es si esto hará más saludables a largo plazo a las marcas que lo hacen de forma sistématica y si la creacion de evento esperado (semejante al superbowl latino) permite pensar en nuevas formas de construir marcas. Y seguir cuestionandonos ¿En qué medida esto podría afectar a la escencia de marca, y por sobre todo la consistencia que exige el modelo de branding 2.0? Y si este hablar y este hacer de una marca la compromete y la proyecta hacia una nueva identidad? 
Y si la respuesta a esto último es sí, entonces tal vez pudiéramos prescindir del canon del manual de marca o estaríamos rompiendo con él y con la hegemonia consensuada de hacer comunicación de marcas en el contexto de la cuarta revolución, la revolucion digital.

\section{Referencias bibliográficas}

Aaker, David A., (2010), Brand Relevance: Making Competitors Irrelevant, EE. UU: Jossey-Bass.

Aaker, Jennifer L., (1997), Dimensions of Brand Personality, EE. UU: Journal of Marketing Research.

Butterfield, Leslie, ed. (1997), Excellence in Advertising, The IPA guide to best practice, Butterworth Heinemann a division of Reed Educational and Professional Publishing Ltd.

Dru Jean- Marie, (2002), Beyond Disruption, Changing the rules in the marketplace, And Adweek Book and John Wiley \& Sons, Inc.

Lane Keller, Kevin, (1999), Brand Mantras: Rationale, Criteria and Examples, EE. UU: Journal of Marketing Management.

Mc Cracken, Grant, (2005), Culture and Consumption II, Indiana University Press.

Michaels, F.S. (2011), Monoculture, How One Story is Changing Everything, Red Clover Press.

Neumeier, Marty, (2005), The Brand Gap: How to Bridge the Distance Between Business Strategy and Design, EE. UU, New Riders.

Otaduy Javier, (2012), Genoma de Marca, Lid.

Rapaille, Clotaire, (2006), The Culture Code, An ingenious way to understand why people around the world live and buy as they do, Broadways Books.

Steel Jon, (2000), Truth, Lies \& Advertising, The art of Account Planning, Adweek Book -Eresma \& Celeste Ediciones.

Wertime, Kent, (2002), Building Brands \& Believers. How to connect with consumers using Archetype. Asia: John Wiley \& Sons.

Pham, Michel Tuan, Maggie Geuens, and Patrick De Pelsmacker (2013), "The Influence of Ad-Evoked Feelings on Brand Evaluations: Empirical Generalizations from Consumer Responses to More than 1000 TV Commercials," International Journal of Research in Marketing, 30 (4), 383-94. Preece, Chloe

Puzakova, Marina and Pankaj Aggarwal (2018), "Brands as Rivals: Consumer Pursuit of Distinctiveness and the Role of Brand Anthropomorphism," Journal of Consumer Research, 45 (4), 869-88.

Reimann, Martin, Sandra Nuñez, and Raquel Castaño (2017), "Brand-Aid," Journal of Consumer Research, 44 (3), 673-91.

Torelli, Carlos J., Rohini Ahluwalia, Shirley Y. Y. Cheng, Nicholas J. Olson, and Jennifer L. Stoner (2017), "Redefining Home: How Cultural Distinctiveness Affects the Malleability of In-Group Boundaries and Brand Preferences," Journal of Consumer Research, 44 (1), 44-61.

Villarroel Ordenes, Francisco, Dhruv Grewal, Stephan Ludwig, Ko De Ruyter, Dominik Mahr, and Martin Wetzels (2019), "Cutting through Content Clutter: How Speech and Image Acts Drive Consumer Sharing of Social Media Brand Messages," Journal of Consumer Research, 45 (5), 988-1012.

https://www.ampagency.com/ Brand EcoSystems. Consultado Enero 2021. https://innovationprotocol.com/ Consultado Enero 2021.

https://the-picnic.com Purpose-driven Growth. Consultado Enero 2021. 
https://www.brandchannel.com/ Always Branding. Always On. Consultado Enero 2021. https://www.folchstudio.com/ Consultado Enero 2021. https://thestoriedbrand.com/ Consultado Enero 2021. https://www.getstoried.com/ Consultado Enero 2021. https://www.interbrand.com/approach/ Consultado Enero 2021.

\section{Algunos Casos emblemátcos}

JoseCuervo, Campaña Calaveras Edición Especial, 2020.

$\mathrm{http}: / /$ cuervotradicional.com.mx/calavera\#

https://open.spotify.com/playlist/3TKuh8TuQFN7pHedV256hC?gclid=CO2zpvXXw6oC-

FSsvmAodhl5xAg

http://www.yucatan.gob.mx/?p=hanal_pixan

https://www.eluniversal.com.mx/cultura/artes-visuales/quien-invento-la-catrina

Nike, Edicion especial, 2020.

https://www.qrtl.com.mx/post/marcas-que-le-entran-a-la-muerte

Martina Garcia. (o9/10/2020). Nike celebra El Día de Muertos con esta colección de sneakers. 23/10/2020, de InStyle Sitio web: https://instyle.mx/moda/nike-dia-de-muertos-coleccion-sneakers/

Fer Rocha. (08/10/2020). Nike lanza colección de sneakers inspirada en El Día de Muertos. 20/10/2020, de El Universal Sitio web: https://www.eluniversal.com.mx/de-ultima/ nike-lanza-una-coleccion-de-tenis- inspirados-en-el-dia-de-muertos

Fernanda Gonzalez. (15/10/2020). Los Nike de Día de Muertos se agotaron y el consumidor ya reaccionó en redes sociales. 20/10/2020, de Merca 2.0 Sitio web: https://www.merca20. com/los-nike-de-dia-de-muertos-se-agotaron-y-el- consumidor-ya-reacciono-en-redes-sociales/

\section{Victoria}

https://www.youtube.com/watch?v=jziyHWsNGIE / https://www.youtube.com/watch?v=CCoTIUdJoFE/

\section{Indio}

https://www.youtube.com/watch?v=LUuJGE6r2LY / https://www.youtube.com/watch?v=R_L7XZygMQE

Barbie:

https://www.youtube.com/watch?v=YbeqO4_sdVo /

https://www.youtube.com/watch?v=3xJ6GLoKSKg

Kellogg's:

https://www.panificacionlatam.com/index.php/productos/26-snacks/3851-kellogg\%E2\%80\%99s-lanza-cereal-de-pan-de-muerto.html /

https://mercadology.mx/2020/og/pan-de-muerto-kelloggs-los-riesgos-del-marketing-yla-cultura-de-la-cancelacion/

\section{La Costeña}

https://www.youtube.com/watch?v=c-OTYaciiCA 
